\title{
Determination of Lamivudine by Precolumn Derivatisation using GC-FID in Pure and Pharmaceutical Dosage Form
}

\author{
Sahithi M. and Gurupadayya B.M.* \\ Department of Pharmaceutical Chemistry, JSS College of Pharmacy, JSS Academy \\ of Higher Education \& Research, Mysuru-570 015, India
}

\begin{abstract}
For the purpose of quantitative estimation of Lamivudine (LMV) in bulk and also pharmaceutical dosage forms a novel method was developed. Ethyl chloroformate (ECF) was used as a precolumn derivitizing reagent. Internal standard employed for this method is Phenylhydrazine (PHZ). GC separation was carried out on a 30 meter length Rtx-5 capillary column (cross bond 5\% diphenyl/ 95\% dimethyl polysiloxane) and an internal diameter of $0.25 \mathrm{~mm}$ aided with flame ionization detector. The elution was carried out at an initial temperature of $100^{\circ} \mathrm{C}$ for one minute at a heating rate of $10^{\circ} \mathrm{C} / \mathrm{min}$ up to $250^{\circ} \mathrm{C}$ and nitrogen flow rate of $2 \mathrm{~mL} / \mathrm{min}$ and a split ratio of $4: 1$, v/v. The linear calibration ranges for LMV was observed between 10-50 ng/mL with corresponding to detection limits of $2 \mathrm{ng}$ reaching the detector. The method developed is later used for the determination of LMV in pharmaceutical preparations. The relative standard deviation (RSD) was found to be $1.53 \%$. The recovery studies were done and the percentage recovery of LMV was found to be $99.2 \%$.

Key words: Gas chromatography, lamivudine (LMV), Phenyl hydrazine (PHZ), Internal standard, Ethyl chloroformate (ECF), Flame ionization detector (FID).
\end{abstract}

\section{Introduction}

Lamivudine (LMV) which is chemically known as (2R-cis)-4-amino-1-(2-hydroxymethyl)-1,3oxathiolan-5-yl-2-(1H)-pyrimidinone-2-deoxy-3-thiacytidine); (Fig.1) is an important active constituent of many pharmaceutical formulations related to treatment of human immunodeficiency virus infector $\mathrm{HIV}^{1-3}$. LMV is also effective counter to hepatitis B virus. LMV is a part of in Martindale, US pharmacopeia and British pharmacopeia.

Alkyl chloroformates are being used as reagents for derivatizing in gas chromatographic determination of amino acids, amines, amino alcohols ${ }^{4-7}$. Literature review acknowledged that some methods were available for the analysis of LMV, in which most methods are of bio-analytical methods for its determination in body fluids. High performance liquids chromatography (HPLC) is an extensively used technique for the estimation of LMV in cerebrospinal fluid ${ }^{8}$, human serum ${ }^{9}$, and blood cells ${ }^{10}$ and for the detection of drug metabolites in rat urine ${ }^{11}$. LMV content in human serum can also be determined by capillary

Gurupadayya B.M. et al /International Journal of PharmTech Research, 2019,12(2): 171-177.

DOI: http://dx.doi.org/10.20902/IJPTR.2019.120212 
electrophoresis ${ }^{12}$. BP and USP method involves of LC method consists of mobile phase is the mixture of 95:5 v/v $0.1 \mathrm{M}$ ammonium acetate and methanol and base deactivated Octadecyl silyl silica gel was used as column stationary phase for the separation of $\mathrm{LMV}^{13,14}$. Some methods for combination drugs of Stavudine and Nevirapine with Lamuvudine were analyzed by HPTLC ${ }^{15}$, with Zidovudine by in tablet dosage forms ${ }^{16}$ and with Abacavir and Zidovudine in tablet dosage forms were all developed by RP-HPLC method ${ }^{17}$.

The objective of this work is to develop and establish a sensitive GC method for the quantitation of LMV as pure drug and thus in pharmaceutical formulations. The present work intended to analyze by capillary GC method for LMV using phenyl hydrazine (PHZ) as an internal standard which is derivatized with ethyl chloroformate (ECF) in FID.

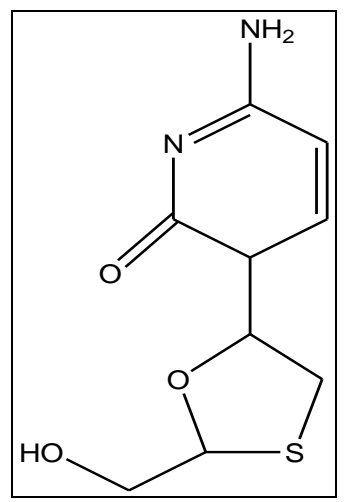

Figure 1: The structure of Lamivudine.

\section{Material and Methods}

\section{Apparatus}

GC analysis was performed on Shimadzu model 2014 (Shimadzu Technologies, Japan) coupled with a split/split less injector, accomplished in a split-mode and with FID detector. The software employed is GC solutions which controlled the gas chromatography program, and a Cannon laser printer was used. Capillary column used is Rtx-5 capillary column (which contains cross bond 5\% dipheny1/95\% dimethyl polysiloxanes) which is 30 meters in length and $0.25 \mathrm{~mm}$ internal diameter.

\section{Reagents and Chemicals}

Analysis was performed on methanol solutions of LMV $(1 \mathrm{mg} / \mathrm{mL})$. The internal standard (IS), phenyl hydrazine was also dissolved in methanol. The standards employed in the research were supplied by Sigma. Methanol used is of analytical grade and was obtained from MERCK (Worli, Mumbai). The carrier gas employed is nitrogen gas at a flow rate of $2 \mathrm{~mL} / \mathrm{min}$. For FID synthetic air at a flow rate of $100 \mathrm{ml} / \mathrm{min}$ was used and hydrogen gas of $25 \mathrm{ml} / \mathrm{min}$ was fed in to the system. The gases used were all of pharmacopoeial purity.

\section{Chromatographic method}

Lamivudine stock solution of $1 \mathrm{mg} / \mathrm{mL}$ concentration was made methanol as solvent. Later, serial dilution is done to get required final. Internal standard phenyl hydrazine $0.05 \mathrm{mg} / \mathrm{mL}$ was prepared.

LMV analysis was performed after derivatization and the internal standard technique was used for computation. For LMV, the method is developed based on its chemical properties. A polar solvent like methanol is used since LMV is also polar. Since the analyte elutes as two symmetrical peaks over a wide range of concentrations, a capillary column which is coated with 5\% diphenyl/ $95 \%$ dimethyl polysiloxane is used. The solutions stored at low temperatures and were protected from light.

\section{Gas Chromatographic determination}

To a solution $(1-5 \mathrm{~mL})$ having LMV $(10-50 \mathrm{ng} / \mathrm{mL})$, and PHZ $(50 \mathrm{ng} / \mathrm{mL})$ was used in a $0.4 \mathrm{ml}$ pyridine solution, and then it is proceeded by $0.5 \mathrm{ml}$ of pure ECF. All these contents were sonicated for about 15 minutes then $0.5 \mathrm{ml}$ chloroform was added. By doing this the layers were separated efficiently. $0.5 \mathrm{ml}$ of extract layer was pipette out with the help of a screw-capped vial. Later the solvent was allowed to evaporate 
and it is later re-dissolved into $0.2 \mathrm{ml}$ of methanol. A $1 \mathrm{ml}$ solution was used and later eluted through the GC capillary column. A manual split injection of $2 \mu \mathrm{l}$ sample was injected with a split ratio of $4: 1$ with inlet temperature of $150^{\circ} \mathrm{C}$. The detector temperature was programmed at $250^{\circ} \mathrm{C}$. After injection the oven temperature was hiked quickly from $50^{\circ} \mathrm{C}$ to $100^{\circ} \mathrm{C}$, which was held for $1 \mathrm{~min}$, then programmed within $5 \mathrm{~min}$ to $250^{\circ} \mathrm{C}$ at a rate of $20^{\circ} \mathrm{C}$ per min which was held for $4 \mathrm{~min}$ and the total run was $10 \mathrm{~min}$.

\section{Procedure for formulation}

The analytical conditions established for reference standards were used for quantitative analysis of selected analytes in pharmaceutical dosage forms. The studies were conducted on the drug LMV, Hepitec (100mg, GSK) and Viramid (100mg, Lupin). Firstly, the tablets were powdered and an quantity equivalent to an average weight of tablet was dissolved in methanol. It is shaken vigorously for about 15 minutes at a speed of 3 cycles/second. This solution was then filtered through a $0.2 \mu$ Whatmann filter paper. The prepared solutions were of concentration 10,30 and $50 \mathrm{ng} / \mathrm{mL}$, sample solution were obtained by mixing of an appropriate amount of the prepared solutions with internal standard solution in methanol and diluting with methanol to the required volume. Further extracted with chloroform and redissolved in methanol as described in the above procedure.

\section{Results and Discussion}

\section{Optimization of reaction conditions}

In order to form a volatile product, LMV and PHZ are treated with ECF which gets eluted and analyzed from the capillary column. Each of LMV and PHZ has single peak. This reaction is performed in presence of methanol. On using an aqueous solution having pyridine as reaction medium, a very good GC result is observed which peak area and average peak height A better GC response (average peak height/peak area) was observed using an aqueous solution containing pyridine as the reaction medium. The effect of $\mathrm{pH}$ 110 was examined for the derivatization at unit interval. It was noticed that derivatization happened at a $\mathrm{pH}$ value more than 6 . Sonication was done at room temperature that is around $30^{\circ} \mathrm{C}$ for about 20 minutes. The reaction mixture the desirable response was observed within $15 \mathrm{~min}$.

Individual chromatograms were recorded for LMV with internal standard. Examples of chromatograms obtained for standard LMV are shown in figure 2, respectively. Based on chromatograms obtained, distinctive retention times corresponding to that internal standard (PHZ) were estimated for the drug on the basis for qualitative identification (Table 1). The chromatogram that was received for the tablet sample is shown in figure 3.

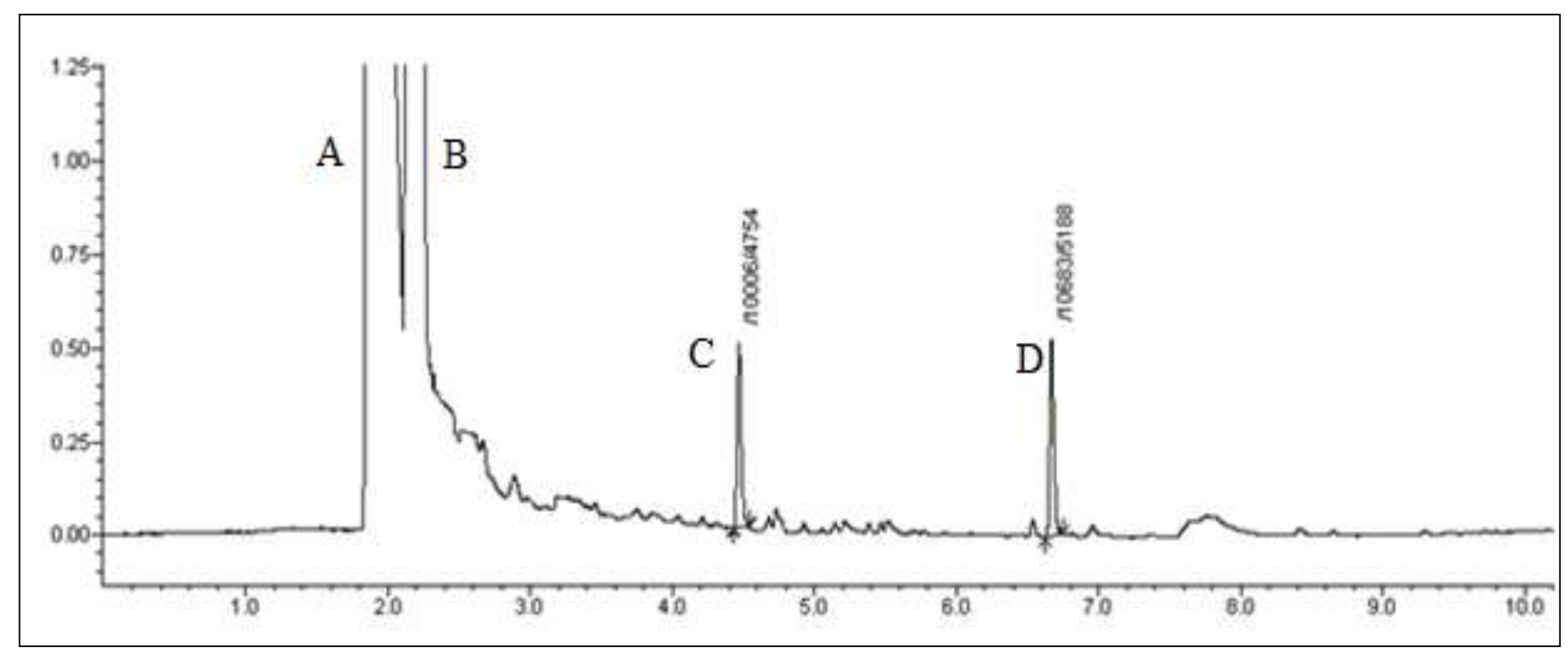

Figure 2: Chromatogram obtained from Lamivudine (LMV) and Phenyl hydrazine (PHZ) solution, Methanol (A), ethyl chloroformate (B), lamivudine (C) and phenyl hydrazine (D). 


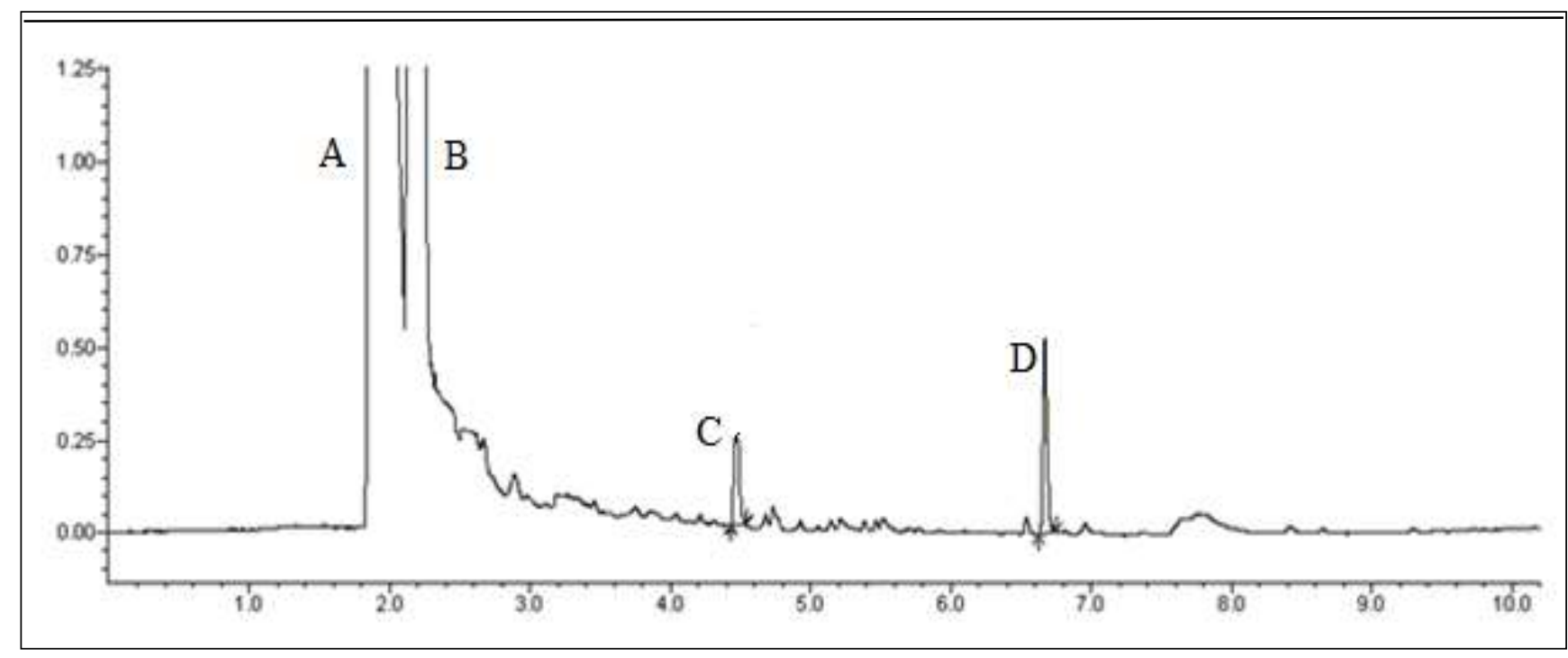

Figure 3: Chromatogram obtained from Lamivudine (LMV) tablet solution. Methanol (A), ethyl chloroformate (B), lamivudine tablet (C) and phenyl hydrazine (D).

Table 1: Chromatographic parameters of LMV

\begin{tabular}{|l|l|}
\hline Parameter & Value \\
\hline Lamivudine (Rt) & $4.5 \mathrm{~min}$ \\
\hline Phenyl hydrazine (Rt) & $6.8 \mathrm{~min}$ \\
\hline Linearity (ng/mL) & $10-50$ \\
\hline LOD (ng) & 0.54 \\
\hline LOQ (ng) & 1.64 \\
\hline Precision & 1.53 \\
\hline Recovery \% & 99.2 \\
\hline
\end{tabular}

\section{Method Validation}

Method validation parameters were established for the above developed method. The validation parameters are accuracy, precision and linearity. A repeatability of a series of six results are considered for precision and inter day results are also calculated. The percentage recovery of three concentrations (can be 80, $100,120 \%$ ) with three replicates each is called accuracy. this is obtained by spiking placebo level with reference standard. By obtaining chromatogram of a series of increasing concentrations gives linearity from which LOD and LOQ are also obtained. Quantitative analysis of the drugs was achieved under well established conditions. The drug of interest Lamivudine was estimated in medicinal products which are in the form of immediate release tablets (Table 1). By comparing the retention time values of the chromatograms of product with those of reference standards, selectivity of the current method is calculated. No additional peaks were found in the chromatogram.

\section{Linearity}

The linearity is plotted between concentrations of LMV on $\mathrm{x}$-axis versus peak area responses on $\mathrm{y}$ axis. The range of concentration varied from 10-50 ng/mL. From this a calibration curve was plotted and correlation co efficient was calculated. The equation of the calibration curve for the slope is $y=9455.3 \mathrm{x}-$ 7855.3 which was calculated from a replicate of six experiments. $r=0.9909$ which indicates the linearity of the method.

\section{Precision}

Precision is called as the repeatability of the method, which was checked within a day (repeatability) and also in different days (intermediate precision). It is obtained by taking chromatograms of three different 
concentration $(10,20,30 \mathrm{ng} / \mathrm{mL})$, each with six repetitions. For checking the limit and extent of precision RSD was calculated, which was found to be $3.02 \%$ for intra-day and $3.82 \%$ for inter-day (Table 2).

\section{Accuracy}

Accuracy was calculated to determine by checking three different concentration levels $(10,15,20$ $\mathrm{ng} / \mathrm{mL}$ ). This is useful to evaluate the interference of additives in the formulation. It is performed by adding known amount of standard pure drug to the previously analyzed formulation dose. A comparison is done by checking the concentration obtained in the spiked samples to the originally added amounts (Table 3 ). This is called \%recovery. Accuracy values are also used in stability studies, which show whether the samples are stable at room temperature, $-20^{\circ} \mathrm{C}$ and $4^{\circ} \mathrm{C}$ refrigeration temperatures over a period of $24 \mathrm{hr}$ which is short term and for $72 \mathrm{hrperiod}$ which is called as long term (Table 4). For this the range of percentages should be between 90-110\%.

Table 2: Precision and accuracy of LMV

\begin{tabular}{|c|c|c|c|c|c|c|}
\hline \multirow{2}{*}{$\begin{array}{l}\text { Added } \\
\text { amount } \\
\text { (ng/mL) }\end{array}$} & \multicolumn{3}{|l|}{ Within-day } & \multicolumn{3}{|l|}{ Between-day } \\
\hline & $\begin{array}{l}\text { Found } \pm \text { SD } \\
(\mathrm{ng} / \mathrm{mL})\end{array}$ & Accuracy & $\begin{array}{l}\text { Precision } \\
\text { RSD\% }^{\mathrm{a}}\end{array}$ & $\begin{array}{l}\text { Found } \pm \text { SD } \\
(\mathrm{ng} / \mathrm{ml})\end{array}$ & Accuracy & $\begin{array}{l}\text { Precision } \\
\text { RSD\% }^{a}\end{array}$ \\
\hline 10 & $10.12 \pm 0.039$ & 3.20 & 3.02 & $9.87 \pm 0.05$ & 4.80 & 3.82 \\
\hline 20 & $20.42 \pm 0.136$ & 1.47 & 1.79 & $20.12 \pm 0.172$ & 2.93 & 2.23 \\
\hline 30 & $31.21 \pm 0.391$ & 4.56 & 1.52 & $30.31 \pm 0.752$ & 5.12 & 2.86 \\
\hline
\end{tabular}

SD: Standard deviation of six replicate determinations, RSD: Relative standard deviation, a average of six replicate determinations, Accuracy: (\%relative error) (found-added)/added x100

Table 3: Recovery values of LMV in pharmaceutical preparations

\begin{tabular}{|l|l|l|l|l|}
\hline \multicolumn{2}{|l|}{ Commercial preparation } & LMV tablet & \multicolumn{2}{|l|}{} \\
\hline \multirow{2}{*}{ Method } & $\begin{array}{l}\text { Added } \\
(\mathbf{n g} / \mathbf{m L})\end{array}$ & $\begin{array}{l}\text { Found } \mathbf{\text { SD }} \\
(\mathbf{n g} / \mathbf{m L})\end{array}$ & Recovery $(\%)$ & RSD\% $^{\text {a }}$ \\
\hline \multirow{3}{*}{ GC-FID } & 10 & $9.52 \pm 0.192$ & 99.0 & 3.78 \\
\cline { 2 - 5 } & 15 & $15.13 \pm 0.263$ & 101.4 & 2.59 \\
\cline { 2 - 5 } & 20 & $20.11 \pm 0.631$ & 102.2 & 2.47 \\
\hline
\end{tabular}

SD: Standard deviation of six replicate determinations, RSD: Relative standard derivation a average of six replicate determinations.

Table 4: Stability of LMV in solution

\begin{tabular}{|c|c|c|c|c|c|c|}
\hline \multirow{2}{*}{$\begin{array}{l}\text { Stability } \\
(\%)\end{array}$} & \multicolumn{2}{|c|}{$\begin{array}{l}\text { Room temperature stability } \\
\text { (recovery } \% \pm \text { SD) }\end{array}$} & \multicolumn{2}{|c|}{$\begin{array}{l}\text { Refrigerator stability, } \\
+4^{\circ} \mathrm{C} \\
(\text { recovery } \% \pm \mathrm{SD})\end{array}$} & \multicolumn{2}{|c|}{$\begin{array}{l}\text { Frozen stability, }-20^{\circ} \mathrm{C} \\
(\text { recovery } \% \pm \mathrm{SD})\end{array}$} \\
\hline & $24 \mathrm{~h}$ & $72 \mathrm{~h}$ & $24 \mathrm{~h}$ & $72 \mathrm{~h}$ & $24 \mathrm{~h}$ & $72 \mathrm{~h}$ \\
\hline 10 & $98.2 \pm 3.76$ & $97.9 \pm 4.18$ & $98.7 \pm 4.25$ & $97.4 \pm 3.24$ & $98.3 \pm 3.2$ & $97.5 \pm 3.22$ \\
\hline 20 & $101.9 \pm 2.85$ & $101.2 \pm 3.98$ & $102.3 \pm 3.59$ & $103.1 \pm 4.42$ & $101.4 \pm 2.56$ & $102.4 \pm 3.23$ \\
\hline
\end{tabular}

\section{Conclusion}

For LMV in the pharmaceutical formulation a simple, suitable, accurate and reliable method was developed with GC-FID and later the method was validated. This method can be applied very effectively 
without any interference with excipients. Hence, this method can be employed for routine GC-FID analysis of LMV formulations.

\section{Acknowledgements}

The authors are thankful Strides Laboratories Ltd., Bangalore, India for providing LMV chemical reference (gift sample) for this study. The authors also thank The Principal, JSS College of Pharmacy, Mysuru, for providing research facilities.

\section{References}

1. Lisotti A., Azzaroli F, Buonfiglioli F, Montagnani M, Flavio Alessandrelli \& Giuseppe Mazzella, Lamivudine treatment for severe acute HBV hepatitis, International Journal of Medical Sciences, 2008; 5 :309-312.

2. Galip Ersoz., Ulus Salih Akarca., Fulya Gunşar \& Zeki Karasu Yücel Batur, Interferon re-treatment for resistance to lamivudine plus interferon treatment, Turkish Journal of Gastroenterology, 2003; 14 : 223-227.

3. Jain R., Jadon N. \& Radhapyari K, Cathodic adsorptive stripping voltammetric studies on lamivudine: an antiretroviral drug, Journal of Colloid and Interface Science, 2007; 313: 254-260.

4. Eunice Kazue Kano., Cristina Helena dos Reis Serra., Eunice Emiko Mori Koono, Simone Schramm Andrade.\& Valentina Porta, Determination of lamivudine in human, plasma by HPLC and its use in bioequivalence studies, International Journal of Pharmaceutics, 2005; 297: 73-79.

5. Husek P J, Amino acid derivatization and analysis in five minutes, FEBS Letters, 1991; 280: 354-356.

6. Md. Yar Khuhawar \& Liaquat Ali Zardari., Ethyl chloroformate as a derivatizing Reagent for the gas chromatographic determination of isoniazid and hydrazine in Pharmaceutical preparations, Analytical Sciences, 2008; 24: 1493-1496.

7. Pithertschatscher K., Hocheriter R., Tthalhamer J. \& Hammerl P, Quantification of histamine in blood plasma and cell culture supernatants: a validated one-step gas Chromatography-mass spectrometry method, Analytical Biochemistry, 2002; 308: 300-306.

8. Roelien Enting H., Norbert Foudraine A., Joep Lange M A., Suzanne Jurriaans., Tom vander Poll., Gerrit-Jan Weverling., Peter Portegies, Cerebrospinal fluid $\beta 2$ - microglobulin, monocyte chemotactic protein-1, and soluble tumour necrosis factor $\alpha$ receptors before and after treatment with lamivudine plus zidovudine or stavudine, Journal of Neuroimmunology, 2000; 102: 216-221.

9. Gholamreza Bahrami., Shahla Mirzaeei., Amir Kiani and Bahareh Mohammadi., High performance liquid chromatographic determination of lamivudine in human serum using liquid-liquid extraction; application to pharmacokinetic studies, Journal of Chromatography B. 2005; 823: 213-217.

10. Yazen Alnouti A. \& Catherine White G. \& Michael Bartlett, Simultaneous Quantitation of Zidovudine and Zidovudine Monophosphate from Plasma, Amniotic Fluid and Tissues by Micellar Capillary Electrophoresis, Journal of Chromatography B, 2004; 803: 279.

11. Nageswara Rao R. \& Dhananjay Shinde D., Two-dimensional LC-MS/MS determination of antiretroviral drugs in rat serum and urine, Journal of Pharmaceutical and Biomedical Analysis, 2009; 50: 994-999.

12. Elisabete Pereira A., Gustavo Micke A., Marina Tavares F M., Determination of antiretroviral agents in human serum by capillary electrophoresis, Journal of Chromatography B, 2005; 1091:169-176.

13. US Pharmacopoeia, Asian Edition 30, United States Pharmacopoeal Convention, Inc, 2007, 2447.

14. Stationery Office (Great Britain), British Pharmacopoeia, HMSO, Vol. 2. Cambridge: International edition; 2007, 1216.

15. Sockalingam Anbazhagan., Narayanareddy Indumathy., Pitchaimuthu Shanmugapandiyan., \& Seshaiah Krishnan Sridhar., Simultaneous quantification of stavudine, lamivudine and nevirapine by UV spectroscopy, reverse phase HPLC and HPTLC in tablets, Journal of Pharmaceutical and Biomedical Analysis, 2005; 39: 801-804.

16. Verweij-van Wissen CPWGM, Aarnoutse R E., Burger DM., Simultaneous determination of the HIV nucleoside analogue reverse transcriptase inhibitors amivudine, didanosine, stavudine, zidovudine and abacavir in human plasma by reversed phase high performance liquid chromatography, Journal of Chromatography B, 2005; 816: 121-219. 
17. Anantha Kumar D, Srinivasa Rao G.\& Seshagiri Rao JVLN, Simultaneous determination of lamivudine, zidovudine and abacavir in tablet dosage forms by RP HPLC method, E- Journal of Chemistry. 2009; 7(1): 180-184. 